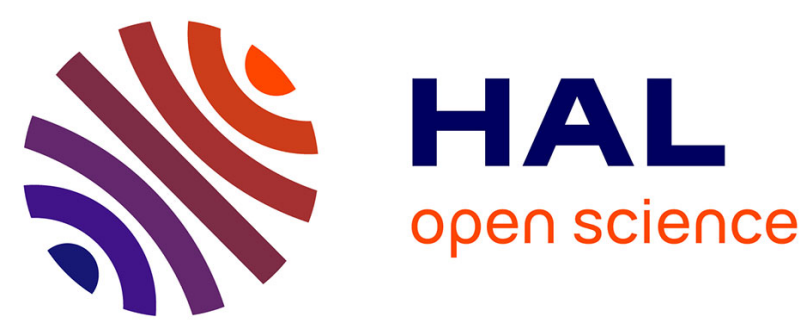

\title{
Lamellipodia nucleation by filopodia depends on integrin occupancy and downstream Rac1 signaling
}

Hervé Guillou, Adeline Depraz-Depland, Emmanuelle Planus, Benoit Vianay, Jacques Chaussy, Alexei Grichine, Corinne Albiges-Rizo, Marc R. Block

\section{- To cite this version:}

Hervé Guillou, Adeline Depraz-Depland, Emmanuelle Planus, Benoit Vianay, Jacques Chaussy, et al.. Lamellipodia nucleation by filopodia depends on integrin occupancy and downstream Rac1 signaling. Experimental Cell Research, 2008, 314 (3), pp.478-488. 10.1016/j.yexcr.2007.10.026 . inserm00263420

\section{HAL Id: inserm-00263420 https://www.hal.inserm.fr/inserm-00263420}

Submitted on 12 Mar 2008

HAL is a multi-disciplinary open access archive for the deposit and dissemination of scientific research documents, whether they are published or not. The documents may come from teaching and research institutions in France or abroad, or from public or private research centers.
L'archive ouverte pluridisciplinaire HAL, est destinée au dépôt et à la diffusion de documents scientifiques de niveau recherche, publiés ou non, émanant des établissements d'enseignement et de recherche français ou étrangers, des laboratoires publics ou privés. 
Lamellipodia nucleation by filopodia depends on integrin occupancy and downstream Rac1 signaling

\author{
Hervé Guillou $^{\mathrm{a}}, \underline{\mathrm{c}}$, Adeline Depraz-Depland $^{\mathrm{a}} \stackrel{\underline{\mathrm{b}}}{ }$, Emmanuelle Planus $^{\mathrm{a}}, \underline{\mathrm{b}}$, Benoit Vianay ${ }^{\mathrm{a}}, \underline{\mathrm{d}}$, \\ Jacques Chaussy ${ }^{\underline{c}}$, Alexei Grichine ${ }^{\underline{a}, \underline{d}}$, , Corinne Albigès-Rizo ${ }^{\underline{a}}, \underline{b}$ and Marc R. Block ${ }^{\underline{a}}, \underline{b}$,
}

\author{
${ }^{a}$ Université Joseph Fourier, Grenoble, France \\ ${ }^{\mathrm{b}}$ INSERM U823, Equipe DySAD, Institut Albert Bonniot, Site Santé, BP170, 38042 \\ Grenoble, France \\ ${ }^{\mathrm{c}}$ CNRS UPR 2940, Institut Néel, BP 166X, 38042 Grenoble Cedex 09, France \\ ${ }^{\mathrm{d} C e l l ~ I m a g i n g ~ P l a t f o r m, ~ I n s t i t u t ~ A l b e r t ~ B o n n o t, ~ L a ~ T r o n c h e ~ C e d e x, ~ F r a n c e ~}$
}

\begin{abstract}
Time-lapse video-microscopy unambiguously shows that fibroblast filopodia are the scaffold of lamellipodia nucleation that allows anisotropic cell spreading. This process was dissected into elementary stages by monitoring cell adhesion on micropatterned extracellular matrix arrays of various pitches. Adhesion structures are stabilized by contact with the adhesive plots and subsequently converted into lamellipodia-like extensions starting at the filopodia tips. This mechanism progressively leads to full cell spreading. Stable expression of the dominantnegative Rac1 N17 impairs this change in membrane extension mode and stops cell spreading on matrix arrays. Similar expression of the dominant-negative Cdc42 N17 impairs cell spreading on homogenous and structured substrate, suggesting that filopodia extension is a prerequisite for cell spreading in this model. The differential polarity of the nucleation of lamellipodial structures by filopodia on homogenous and structured surfaces starting from the cell body and of filopodia tip, respectively, suggested that this process is triggered by areas that are in contact with extracellular matrix proteins for longer times. Consistent with this view, wild-type cells cannot spread on microarrays made of function blocking or neutral anti$\beta_{1}$ integrin antibodies. However, stable expression of a constitutively active Rac1 mutant rescues the cell ability to spread on these integrin microarrays. Thereby, lamellipodia nucleation by filopodia requires integrin occupancy by matrix substrate and downstream Rac1 signaling.
\end{abstract}

Keywords: Matrix; Spreading; Protein patterning; Lithography; Filopodia; Actin; Stress fibers; Focal adhesion

Abbreviations: FN7-10, fragment of fibronectin comprising type III domains 7 to 10; FITC, fluorescein isothiocyanate; TRITC, tetramethyl rhodamine isothiocyanate; $\alpha$-MEM, minimal essential medium with alpha modification; DMEM, Dulbecco's modified essential medium; EDTA, ethylene diamine tetra acetic acid; PBS, phosphate-buffered saline 


\section{Introduction}

Cell adhesion to extracellular matrix plays a key role in cell physiological processes including motility, anoikis and proliferation. These processes are essential for embryonic development, wound healing or inflammation. Although it usually takes more than $1 \mathrm{~h}$ for fibroblast cells to achieve spreading with mature focal adhesions, the initial steps of this process are much faster [1] and [2]. The early stages of cell spreading involve two types of membrane protrusions: actin-rich veils named lamellipodia and finger-like projections called filopodia. Initial steps of spreading are thought to share molecular processes with membrane extensions at the leading edge of motile cells that are fundamental for cell guidance [1], [3] and [4]. Increasing knowledge has been accumulated about the molecular regulation of actin dynamics including the control of lamellipodia and filopodia extensions [5] and [6] by the G protein Rac1 and Cdc42, respectively, the nucleation of microfilaments by the Arp2/3 complex [7], [8] and [9] and the anti-capping activity of the Ena/VASP protein family [10] and [11]. However, little is known about the role of cell adhesion onto extracellular matrix although a recent report indicated the presence of integrins in filopodia playing a major role in cell adhesion [12]. In membrane protrusions, it has also been suggested that integrins might be activated but still unliganded [13]. Indeed, the interplay between lamellipodia and filopodia during cell spreading and motility is still controversial. The classical view is that the primary function of filopodia is to sample the immediate environment and to transduce signals that trigger the extension of lamellipodia in a distinct process [14] and [15]. The choice between one and the other mode in actin polymerization would be dependent on the capping protein at the barbed end [16]. Alternatively, it was proposed that merging of convergent lamellipodia would result in the bundling of actin filament that would initiate filopodia formation [17]. However, nucleation of membrane veils (that are very similar in structure to lamellipodia) from filopodia originated from the growth cone has recently been described [18]. The lack of experimental evidence that could strengthen one hypothesis to the other is mostly due to the highly dynamic nature of cell membrane protrusions. Indeed, the speed of lamella protrusion and retraction is about $0.4 \mu \mathrm{m} / \mathrm{s}$ [19], whereas the speed of filopodia extension at the growth cone ranges from 0.1 to $0.2 \mu \mathrm{m} / \mathrm{s}$ [20]. Until the recent progress of optical microscopy, this high speed associated with the small size of the structures made measurements and time-lapse video uneasy. Moreover, filopodia are very thin structures that are barely visible with classical microscopy techniques. Finally, the highly irregular shape of the cells and the cycles of extensions and retractions of the membrane have blurred the observation of possible rules that may govern cell spreading although careful microscopy analyses suggest that such rules do exist [17] and [21].

Constraining cell adhesion to micrometric adhesive islands separated by anti-adhesive surfaces creates reproducible geometric cell shapes and controls cell physiology. Pioneering studies from the groups of Donald Ingber and Georges Whitesides have shown that constraining cell shape using micrometer-sized extracellular matrix islands resulted in the regulation of proliferation and apoptosis [22] and [23]. Simplifying cell geometry helps observations of the sequential steps and discloses important rules of cell behavior and cytoskeleton dynamics. For instance, it was shown that cells cultured on square matrix islands preferentially extended lamellipodia from their corners [24] or that spatial distribution of the matrix has a role in determining the orientation of the division axis of HeLa cells [25].

Here, we have analyzed fibroblast spreading onto fibronectin fragment by fast videomicroscopy. Movies unambiguously indicated that filopodia nucleates lamellipodia on their sides. This nucleation starts from the cell body and moves to the filopodia tips. To dissect this 
process into discrete stages, we used micrometric matrix protein arrays to follow adhesion of NIH 3 T3 cells. With such patterns, the anchorage points of subcellular size are spatially defined and limited in number. Conversely to the commonly used large patterned adhesive surfaces that restrain the cell spreading to predetermined geometrical shapes [23] and [26], matrix protein microarrays allow a higher degree of freedom since the cells can choose between numbers of elementary shapes that may depend on the constraints of actin cytoskeleton assembly. Moreover, the processes of membrane extensions and cell attachment to the extracellular matrix are spatiotemporally disconnected. Time-lapse video-microscopy unambiguously shows that fibroblasts spreading on microstructured matrix protein arrays primarily use filopodia to reach new adhesive surfaces. At the contact of adhesive surfaces, these structures are stabilized and subsequently nucleate lamellipodia-like extensions that lead to full spreading. We have shown that this process depends on integrin occupancy and downstream Rac1 signaling.

\section{Materials and methods}

\section{Cell culture}

NIH 3 T3 fibroblasts were cultured in $\alpha$-MEM (Gibco-InVitrogen, Oxon, UK) supplemented with $10 \%$ inactivated fetal calf serum, penicillin and streptomycin and were harvested with trypsin/EDTA. Cells were plated with 60,000 cells in $2 \mathrm{ml}$ on microstructured arrays (area of $440 \mathrm{~mm}^{2}$ ) in 30-mm Petri dishes and were left to spread for $4 \mathrm{~h}$. For cells stably expressing GFP-RacV12 or GFP-RacN17, cells at 50\% confluence were starved in $\alpha$-MEM without fetal calf serum overnight before plating on patterned substrates in $\alpha$-MEM complemented with serum.

\section{Immunostaining}

Cells were fixed in PBS with 3\% paraformaldehyde supplemented with $2 \%$ sucrose and were permeabilized with $0.2 \%$ Triton X-100 in PBS. Nonspecific sites were blocked with PBS and $10 \%$ goat serum for at least $45 \mathrm{~min}$ at $37^{\circ} \mathrm{C}$. Monoclonal anti-vinculin (clone VIN-11-5, Sigma, l'Isle d'Abeau, France) or anti-Rac1 (clone 102 Transduction Laboratories, Becton Dickinson, Le Pont de Claix, France) were used for focal adhesions and lamellipodia staining, respectively. Tetramethyl rhodamine isothiocyanate (TRITC)-phalloidin (Sigma-Aldich) was used for F-actin visualization. Cells were observed with an Olympus Provis AX70 microscope (Olympus division Bio, Rungis, France) with a $60 \times$ planapo objective (N.A. 1.4).

\section{Retroviral cell infections}

The coding cDNAs for Rac1 N17, Rac1 V12, Cdc42 N17 and Cdc42 V12 cloned into the pBabe GFPpuro vector were a gift from Dr C. Gauthier-Rouvière (CRBM Montpellier France). Phoenix cells grown in DMEM in $10 \mathrm{~cm}$ Petri dishes at $30-40 \%$ confluence were transfected with pBabe Rac1 or Cdc42 vectors using EXGEN 500 (Euromedex, Souffelweyersheim, France) according to the manufacturer's recommendations. After $24 \mathrm{~h}$, the medium was removed and replaced by $5 \mathrm{ml}$ of fresh medium. After 48,72 and $96 \mathrm{~h}$, the medium containing the virions is withdrawn and filtered onto a $0.20-\mu \mathrm{M}$ cellulose acetate disposable filter and frozen in aliquot fractions before use.

For viral infections, $1 \mathrm{ml}$ of DMEM containing the virions and supplemented with $10 \mu \mathrm{g} / \mathrm{ml}$ of polybrene was deposited onto on $30-40 \%$ confluent NIH 3 T3 cells in 6-well plates. An 
additional milliliter of fresh DMEM was then poured into the well to reach a final volume of $2 \mathrm{ml}$. After 4 to $6 \mathrm{~h}$ of incubation at $37^{\circ} \mathrm{C}$, a second round of infection was carried out similarly. Forty-eight hours after infection, puromycin was added at the concentration of $1 \mu \mathrm{g} / \mathrm{ml}$ to allow the selection of infected cells. FACS analysis of GFP expression revealed that the population was homogenous after 2 weeks of selection.

\section{Video-microscopy}

Microstructured arrays were fixed on a 30-mm Petri dish and 60,000 cells in $2 \mathrm{ml}$ were plated. The dish was positioned on a motorized stage of an inverted 200M Zeiss microscope (Carl Zeiss, LePecq, France) equipped with a fast filer wheel and a CoolSnap HQ2 camera (Roper Scientific, Evry, France). During the experimental stage, temperature and $\mathrm{CO}_{2}$ content of the atmosphere were regulated at $37^{\circ} \mathrm{C}$ or $25^{\circ} \mathrm{C}$ and $5 \%$, respectively.

\section{Pattern microfabrication and functionalization}

Cleaned glass cover slips $(22 \times 22 \mathrm{~mm})$ were dipped for $1 \mathrm{~h}$ in a solution of octadecyltrichlorosilane (Sigma-Aldrich, L'isle d'Abeau, France) and hexane $0.2 \% \mathrm{v}: \mathrm{v}$. The $\mathrm{SiCl}_{3}$ group of the alkylsilane reacts with the silanol groups present on the glass surface and optical measurements of water contact angles between $100^{\circ}$ and $110^{\circ}$ indicate the formation of robust multilayers of long hydrophobic carbon chains [27]. Positive photoresist resin (Shipley, S1805, Rhom \& Haas Electronic Materials, Villeurbane, France) was spin-coated and cured according to the manufacturer's protocol to form a uniform UV-sensitive film $0.5 \mu \mathrm{m}$ in thickness. The cover slips coated with photoresist resin were then irradiated with UV light Karl Süss aligner MJB3, SUSS MicroTec, Saint-Jeoire, France) at $436 \mathrm{~nm}$ and $15 \mathrm{~mJ} / \mathrm{cm}^{2}$ through a chromium mask, and the irradiated pattern was revealed with microposit developer in pure water 1:1 (Shipley, MF CD-26, Rhom \& Haas Electronic Materials, Villeurbane, France). The glass cover slips with patterned photoresist resin were incubated for $1 \mathrm{~h}$ at $37^{\circ} \mathrm{C}$ in a solution of the Fluorecein isothiocyanate (FITC)-labeled cellular interaction fragment of fibronectin made of type III domains 7 to 10 (FN7-10) [28] at the concentration ranging from 5 to $15 \mu \mathrm{g} / \mathrm{ml}$ in PBS. Nonspecific adsorption on glass or silicon of fibronectin is approximately self-limited to a monolayer [29] and the hydrophobicity of the substrate increases the protein packing and consequently the layer homogeneity [30]. The substrates were then rinsed in PBS and subsequently in pure ethanol in an ultrasonic water bath to dissolve the photoresist resin. Finally, on the complementary pattern revealed after resin dissolution by ethanol, anti-adhesive tri-block polymer Pluronic F127 ${ }^{\mathrm{TM}}$ (Sigma-Aldrich) [31] ( $4 \%$ in water, $1 \mathrm{~h} 30 \mathrm{~min}$ at $37^{\circ} \mathrm{C}$ ) were adsorbed. A final rinsing in PBS is the final step of the pattern microfabrication of the cover glasses now ready for use. Alternatively, protein coating with $15 \mu \mathrm{g} / \mathrm{ml}$ of either a function blocking anti- $\beta_{1}$ monoclonal antibody (Clone $\mathrm{Ha}$ $2 / 5$, from Becton Dickinson, Le Pont de Claix, France) or neutral anti- $\beta_{1}$ monoclonal antibody (Clone MA 1.2 from Chemicon, AbCys Paris, France) was carried out. After functionalization of the cover slips, these antibodies remained fully functional.

\section{Results}

\section{Nucleation of Iamellipodia by filopodia}

Video-microscopy of spreading NIH 3T3 cells on homogenous FN7-10 coat under a 2-s time lapse was carried out. As previously described, the cells adopt randomly either an isotropic spreading mode with mostly lamellipodia extension or an anisotropic mode by issuing 
filopodia and lamellipodia [32]. In this second mode, time-lapse analysis revealed that most lamellipodia were issued from preexisting filopodia. The swelling usually occurred about $1 \mathrm{~min}$ after the filopodia extension and started from the cell body (i․ 1 and Supplementary Movie 1).

To decipher the mechanism of anisotropic cell spreading, we have studied cell spreading on protein microarrays with adhesive spots of $4 \times 4 \mu \mathrm{m}$ made of FN7-10 and separated by antiadhesive surfaces of polyethylene oxide as described under Materials and methods. On these surfaces, the final shape of spread cells is not predetermined since the cells can use one adhesive spot or another. Indeed, when the lateral distance between two consecutive islands was no more than $8 \mu \mathrm{m}$, NIH 3T3 cells attached and spread on the array in a manner similar to that usually observed on uniformly coated surfaces (Fig. 2A, left panels) and in good agreement with previous data [23], whereas when the distance between adhesive islands increased to $10,12,14$ or $16 \mu \mathrm{m}$, most of the cells adopted simplified polygonal shapes (Fig. $\underline{2}$ A, right panels). Finally, at a pitch of $20 \mu \mathrm{m}$ or above, the cells were unable to spread on the substrate (not shown). Monitoring the stages of cell spreading from 0 to $90 \mathrm{~min}$ by videomicroscopy on patterned surfaces revealed that cells use mostly the anisotropic mode for spreading. Once a filopodium reached a matrix spot, adhesion prevented retraction and the filopodium tip in contact with the adhesive plot began to swell up (Fig. 2B) similar to what was observed on homogenous substrate but in the opposite direction: The extending membrane veil occurred from the tip toward the cell body and quickly occupied the space between the nearby adhesive spots (Fig. 2B and Supplementary Movies 2 and 3 ).

\section{Characterization of membrane protrusion nucleated from filopodia on protein arrays}

A careful examination of the filopodia swelling tips reveals the presence of focal complexes recruiting vinculin behind the membrane extension (Fig. $3 \mathrm{~A}$, upper panel, and $\underline{3} \mathrm{~B}$ ). From a biochemical point of view, the observed accumulation of vinculin into focal complexes during the swelling of the filopodia was also consistent with the distinct nature of these membrane protrusion since this protein is not normally found in filopodia [33]. Moreover, cell immunolabeling using an anti-Rac monoclonal antibody, a marker of lamellipodia edges, was carried out. It showed that this Rho-GTPase accumulated at the swelling tips of filopodia (Fig. $\underline{3}$ A, lower panel, white arrows). Using stable transfection of the constitutively active Rac mutant V12 fused with GFP and video-microscopy, Rac accumulation was also observed at the swelling tips of filopodia (Supplementary Movies 4A and 4B). Finally, TRITC-phalloidin staining of F-actin revealed actin polymers beneath the plasma membrane at the swelling tip of filopodia (Fig. 3B), suggesting that the membrane extension was an active process and not blebbing due to local pressure increase. Filopodia and lamellipodia formation are mediated by Cdc42 and Rac1, respectively. It is believed that the activation of Cdc42 leads to the subsequent activation of Rac 1 [5] and [34] and that both GTPases are required for full spreading [34]. The observation that the switch in actin polymerization mode only occurred at areas of matrix in contact with the cells suggested that integrin occupancy could play an important role in this process, possibly through Racl activation generating lamellipodia extension.

\section{Filopodia extension is a prerequisite of spreading on FN7-10 in 3T3 cells}

When analyzing the membrane dynamics of NIH $3 \mathrm{~T} 3$ cells on micropatterned matrix, filopodia extensions seemed to precede lamellipodia formation during anisotropic cell spreading. To check whether this filopodia are prerequisite cell spreading, we carried out 
stable transfection of the dominant-negative mutant Cdc42 N17 and allowed the polyclonal cell population to spread on homogenous or micropatterned coat of FN7-10. Even on homogenous coat, Cdc42 N17 expression results in a severe impairment of cell spreading on this fibronectin fragment (Fig. 4A), indicating that under these experimental conditions, anisotropic spreading mode is predominant in this cell type. Quantification of spreading inhibition was achieved by measuring the number spread cells per surface unit on matrix microarrays of various pitches (Fig. 4B). Indeed, increasing the pitch reduced the number of spread cell, suggesting that filopodia extension progressively became a limiting step of the adhesion process while cell spreading was more and more dependent on the anisotropic mode. Again, Cdc42 N17 expression resulted in a marked decrease in cell spreading compared to Cdc42 V12 transfected cells.

\section{Lamellipodia nucleation from filopodia depends on Rac1 signaling}

To confirm that filopodia swelling was the result of an actual switch in GTPase signaling, we generated stable NIH $3 \mathrm{~T} 3$ cell populations expressing either the dominant-positive or negative form of Rac1, GFP-RacV12 and GFP-RacN17, respectively, using retroviral infection. On matrix protein arrays, either a small pitch of $8 \mu \mathrm{m}$ or a homogenous-coated matrix, both cell populations attached and spread on the support. However, increasing the interval between adhesive plots resulted in a dramatic change in adhesion behavior of these two cell populations. Cells expressing the constitutively active and tagged form of Rac1, GFP-Rac V12 were able to spread and adopted geometrical shapes on protein arrays whatever the pitch value of the protein array ranging from 12 to $16 \mu \mathrm{m}$ (Figs. 5A, C, E). As expected for a Rac1-induced phenotype, large lamellipodia were generated from the whole cell periphery (Fig. 5C). Conversely, expression of the dominant-negative GFP-RacN17 still allowed cell attachment but no spreading on those protein arrays with identical pitch (Fig. $\underline{5}$ F). Closer view of the cells at high magnification revealed that the cells generated a great number of filopodia that could be attached to the neighboring adhesive islands but none of them exhibited any swelling (Fig. 5B). DIC microscopy showed that each filopodia exhibited a little bulge at its tip (Fig. 5D) and time-lapse video-microscopy revealed no swelling of these areas during the time course of the experiment (not shown). Altogether, these data strongly suggest that filopodia swelling is dependent on Rac1 activity and represents a true switch in GTPase signaling. Therefore, Racl seems to be essential for lamellipodia nucleation from scaffolding filopodia but not required for filopodia extension.

\section{Integrin occupancy mediates Rac1 downstream activation that triggers lamellipodia nucleation from filopodia}

On patterned surfaces, the lack of adhesive surface available next to the cell body renders more obvious the switch in the actin polymerization mode at filopodia since it was clear that it was not the cell body but the filopodium itself that expanded during the process of spreading. It also unambiguously demonstrated the requirement of cell matrix contact to trigger this nucleation suggesting that integrin occupancy plays a major role to initiate this process. Indeed, on homogenous substrates, integrins at the cell body periphery were occupied for a longer time compared to those located at the filopodia tips. Thereby, if outside-in integrin signaling is required for mediating an activation of Rac1, such activation should be triggered at the filopodia roots for cells located on homogenous substrates and conversely at the filopodium tip reaching an adhesive plot with cells spreading on a patterned matrix. To verify this hypothesis, we used a patterned substrate coated with either a function blocking anti- $\beta_{1}$ monoclonal antibodies. Both wild-type and GFP-RacV12 expressing cells attached and spread 
on homogenous coating made of antibodies in an undistinguishable manner (Fig. 6B). This sharply contrasts with the inability of wild-type NIH 3T3 cells to spread on arrays made of these anti- $\beta_{1}$ antibodies (Figs. 6A, B). However, constitutively active GFP-RacV12 expression rescued the ability of the cell to spread on anti- $\beta_{1}$ antibodies coated arrays (Figs. $\underline{6}$, B). These results indicate that Rac1 is acting downstream integrin signaling and is necessary to trigger cell spreading on discontinuous adhesive substrates, consistent with video-microscopy observations. Identical results were observed with a neutral monoclonal antibody (not shown).

\section{Discussion}

Fibroblasts can spread using isotropic or anisotropic modes [32]. When the anisotropic mode is chosen, fast video-microscopy clearly shows that filopodia nucleates lamellipodia extensions. On matrix protein arrays, NIH 3 T3 cells adopt geometrical shapes with simplified actin cytoskeleton architecture and adhesive site pattern that allow actin dynamics to be decomposed into discrete elementary steps and thereby giving insight into the molecular mechanisms of cell spreading. Cells on discontinuous extracellular matrix favor the anisotropic mode for spreading. Under these conditions, this process can be dissociated into two consecutive stages: First, the extension of a filopodium that is stabilized once it encounters an adhesive plot; second, an actin driven membrane enlargement at the tip of the filopodium in contact with extracellular matrix proteins. These data are consistent with recent reports indicating that, with NIH $3 \mathrm{~T} 3$ cells, filopodia are among the membrane extensions the adhesion precursors that provide the initial contacts with the substratum [12] and that at the growth cone, filopodia nucleates veils that are similar to lamellipodia [18]. It has also been suggested that filopodia are created from convergent propagation of the lamellipodial actin network [17]. Although such a transition from dendritic actin polymerization into actin bundles has been reconstituted in vitro in a cell-free system [35], recent data have reported the formation of filopodia in the absence of functional WAVE and Arp2/3 complexes in mammalian and Dictyostelium discoideum cells, indicating that lamellipodia and filopodia can be functionally distinct [36]. Moreover, this model predicts that lamellipodia protrusion would be a prerequisite for membrane spreading that is obviously not the case at least for fibroblast NIH $3 \mathrm{~T} 3$ cells on which the stages of spreading were accurately analyzed [12]. However, the convergent propagation model may account for filopodia initiation also dependent on myosin $\mathrm{X}$ motor activity [37].

When the lateral distance between adhesive spots was increased up to $20 \mu \mathrm{m}$, the cells attached to some adhesive island but failed to spread (not shown), suggesting that there is a physical limit to filopodia extension, and that this latter process is required for spreading. On the other hand, Rac1 inhibition by expression of the dominant-negative GFP-Rac N17 results in the inability of the cells to spread on protein arrays with large pitch, but not on arrays with small pitch or homogenous matrix coat. This suggests that cells can also use a lamellipodium independent alternative for spreading. It has been suggested that such process could result from the reorientation of mature focal adhesions and connected actin stress fibers within neighboring filopodia that would push the cell borders between consecutive membrane extensions without any need of Rac mediated lamellipodia [12]. Cross-linking between stress fibers anchored to focal adhesions and contractile transverse actin arcs may be essential to reorient the stress fibers and thereby to generate this type of spreading [38] and may not occur on a patterned surface on which the cell body is not entirely in contact with the matrix. The ability of GFP-Rac N17-infected cells to extend filopodia and to anchor filopodia to adhesive plots also shows that Rac1 is neither necessary for filopodia extension during the exploration 
of matrix environment nor for matrix initial attachment. We can also conclude that filopodia extensions are precursors of lamellipodia.

Our data also indicate that lamellipodia nucleation by filopodia requires integrin occupancy and downstream Rac1 activation. Indeed, Rac1 activation by integrin engagement has been demonstrated [34]. A number of activation pathways have been proposed including the implication of the exchange factor Vav2 [39], integrin-linked kinase- $\beta$-parvin recruitment of the exchange factor $\alpha$-PIX [40] or targeting of the GTPase through the paxillin/GIT/ $\beta$-PIX complex [41]. Alternatively, integrins may regulate Rac1 targeting by controlling cholesterolrich membrane domains that are essential to the GTPase translocation to the cell plasma membrane [42] and [43]. Altogether, these results allow to define the sequential molecular events controlling fibroblast spreading in the anisotropic mode, i.e., filopodia extension, integrin engagement, Rac 1 activation, lamellipodia nucleation.

In contact with adhesive substrate, integrins at the tip of filopodia assemble bona fide focal adhesions containing vinculin a protein that is not normally present in these membrane extensions [33]. Thereby, focal adhesion assembly to form nascent adhesive structure would require fast transport of their components along the filopodium body. Integrin $\beta_{1}$ chain relocalization at the filopodia and Mena/VASP complex requires myosin X motor [44] and [45]. Although myosin $\mathrm{X}$ activity promotes filopodia formation independently from integrin occupancy [46], it is conceivable that this molecular motor plays a major role in bringing to the filopodium tip the molecular components of focal adhesions, possibly under the control of outside-in integrin signaling.

\section{Acknowledgments}

This work was supported in part by the program AC "Dynamique et réactivité des assemblages biologiques" and by the Institute for Nano Sciences of Grenoble. ADD is a recipient of a doctoral fellowship from the Ministère de l'enseignement supérieur et de la recherche. We thank Professor Bertrand Fourcade for helpful discussions, Dr. Cécile Gauthier-Rouvière for providing us with the retroviral constructs and André, J.-L. Garden and P. Lachkar from the Pôle de Capteurs Thermiques pour la Calorimétrie (MCBT, Institut NéelCNRS UPR 2940 Grenoble, France) for their technical assistance.

\section{References}

[1] R. Zaidel-Bar, C. Ballestrem, Z. Kam and B. Geiger, Early molecular events in the assembly of matrix adhesions at the leading edge of migrating cells, J. Cell Sci. 116 (2003), pp. 4605-4613.

[2] L. Tranqui, Y. Usson, C. Marie and M.R. Block, Adhesion of CHO cells to fibronectin is mediated by functionally and structurally distinct adhesion plaques, J. Cell Sci. 106 (Pt 1) (1993), pp. 377-387. 
[3] Y. Zhang, K. Chen, L. Guo and C. Wu, Characterization of PINCH-2, a new focal adhesion protein that regulates the PINCH-1-ILK interaction, cell spreading, and migration, $J$. Biol. Chem. 277 (2002), pp. 38328-38338.

[4] L. Zeng, X. Si, W.P. Yu, H.T. Le, K.P. Ng, R.M. Teng, K. Ryan, D.Z. Wang, S. Ponniah and C.J. Pallen, PTP alpha regulates integrin-stimulated FAK autophosphorylation and cytoskeletal rearrangement in cell spreading and migration, J. Cell Biol. 160 (2003), pp. 137146.

[5] C.D. Nobes and A. Hall, Rho, rac, and cdc42 GTPases regulate the assembly of multimolecular focal complexes associated with actin stress fibers, lamellipodia, and filopodia, Cell 81 (1995), pp. 53-62.

[6] A.J. Ridley, H.F. Paterson, C.L. Johnston, D. Diekmann and A. Hall, The small GTPbinding protein rac regulates growth factor-induced membrane ruffling, Cell 70 (1992), pp. 401-410.

[7] L.M. Machesky and R.H. Insall, Scar1 and the related Wiskott-Aldrich syndrome protein, WASP, regulate the actin cytoskeleton through the Arp2/3 complex, Curr. Biol. 8 (1998), pp. $1347-1356$.

[8] R. Rohatgi, L. Ma, H. Miki, M. Lopez, T. Kirchhausen, T. Takenawa and M.W. Kirschner, The interaction between N-WASP and the Arp2/3 complex links Cdc42-dependent signals to actin assembly, Cell 97 (1999), pp. 221-231.

[9] T.E. Stradal and G. Scita, Protein complexes regulating Arp2/3-mediated actin assembly, Curr. Opin. Cell Biol. 18 (2006), pp. 4-10.

[10] M. Krause, J.E. Bear, J.J. Loureiro and F.B. Gertler, The Ena/VASP enigma, J. Cell Sci. 115 (2002), pp. 4721-4726.

[11] J.E. Bear, T.M. Svitkina, M. Krause, D.A. Schafer, J.J. Loureiro, G.A. Strasser, I.V. Maly, O.Y. Chaga, J.A. Cooper, G.G. Borisy and F.B. Gertler, Antagonism between Ena/VASP proteins and actin filament capping regulates fibroblast motility, Cell 109 (2002), pp. 509-521.

[12] M.A. Partridge and E.E. Marcantonio, Initiation of attachment and generation of mature focal adhesions by integrin-containing filopodia in cell spreading, Mol. Biol. Cell 17 (2006), pp. 4237-4248.

[13] C.G. Galbraith, K.M. Yamada and J.A. Galbraith, Polymerizing actin fibers position integrins primed to probe for adhesion sites, Science 315 (2007), pp. 992-995.

[14] R.W. Davenport, P. Dou, V. Rehder and S.B. Kater, A sensory role for neuronal growth cone filopodia, Nature 361 (1993), pp. 721-724.

[15] A.J. Koleske, Do filopodia enable the growth cone to find its way $\diamond$, Sci. STKE 2003 (2003), p. e20. 
[16] M.R. Mejillano, S. Kojima, D.A. Applewhite, F.B. Gertler, T.M. Svitkina and G.G. Borisy, Lamellipodial versus filopodial mode of the actin nanomachinery: pivotal role of the filament barbed end, Cell 118 (2004), pp. 363-373.

[17] T.M. Svitkina, E.A. Bulanova, O.Y. Chaga, D.M. Vignjevic, S. Kojima, J.M. Vasiliev and G.G. Borisy, Mechanism of filopodia initiation by reorganization of a dendritic network, J. Cell Biol. 160 (2003), pp. 409-421.

[18] A.K. Mongiu, E.L. Weitzke, O.Y. Chaga and G.G. Borisy, Kinetic-structural analysis of neuronal growth cone veil motility, J. Cell Sci. 120 (2007), pp. 1113-1125.

[19] B. Hinz, W. Alt, C. Johnen, V. Herzog and H.W. Kaiser, Quantifying lamella dynamics of cultured cells by SACED, a new computer-assisted motion analysis, Exp. Cell Res. 251 (1999), pp. 234-243.

[20] V. Argiro, M.B. Bunge and M.I. Johnson, A quantitative study of growth cone filopodial extension, J. Neurosci. Res. 13 (1985), pp. 149-162.

[21] M. Steketee, K. Balazovich and K.W. Tosney, Filopodial initiation and a novel filamentorganizing center, the focal ring, Mol. Biol. Cell 12 (2001), pp. 2378-2395.

[22] R. Singhvi, A. Kumar, G.P. Lopez, G.N. Stephanopoulos, D.I. Wang, G.M. Whitesides and D.E. Ingber, Engineering cell shape and function, Science 264 (1994), pp. 696-698.

[23] C.S. Chen, M. Mrksich, S. Huang, G.M. Whitesides and D.E. Ingber, Geometric control of cell life and death, Science 276 (1997), pp. 1425-1428.

[24] K.K. Parker, A.L. Brock, C. Brangwynne, R.J. Mannix, N. Wang, E. Ostuni, N.A. Geisse, J.C. Adams, G.M. Whitesides and D.E. Ingber, Directional control of lamellipodia extension by constraining cell shape and orienting cell tractional forces, FASEB J. 16 (2002), pp. 1195-1204.

[25] M. Thery, V. Racine, A. Pepin, M. Piel, Y. Chen, J.B. Sibarita and M. Bornens, The extracellular matrix guides the orientation of the cell division axis, Nat. Cell Biol. 7 (2005), pp. 947-953.

[26] K. Kandere-Grzybowska, C. Campbell, Y. Komarova, B.A. Grzybowski and G.G. Borisy, Molecular dynamics imaging in micropatterned living cells, Nat. Methods 2 (2005), pp. 739-741.

[27] H. Sorribas, C. Padeste and L. Tiefenauer, Photolithographic generation of protein micropatterns for neuron culture applications, Biomaterials 23 (2002), pp. 893-900.

[28] D.J. Leahy, I. Aukhil and H.P. Erickson, 2.0 A crystal structure of a four-domain segment of human fibronectin encompassing the RGD loop and synergy region, Cell 84 (1996), pp. 155-164.

[29] L. Guemouri, J. Ogier, Z. Zekhini and J.J. Ramsden, The architecture of fibronectin at surfaces, J. Chem. Phys. 113 (2000), pp. 8183-8186. 
[30] H. Sorribas, C. Padeste and L. Tiefenauer, Photolithographic generation of protein micropatterns for neuron culture applications, Biomaterials 23 (2002), pp. 893-900.

[31] V.A. Liu, W.E. Jastromb and S.N. Bhatia, Engineering protein and cell adhesivity using PEO-terminated triblock polymers, J. Biomed. Materi. Res. 60 (2002), pp. 126-134

[32] B.J. Dubin-Thaler, G. Giannone, H.G. Dobereiner and M.P. Sheetz, Nanometer analysis of cell spreading on matrix-coated surfaces reveals two distinct cell states and STEPs, Biophys. J. 86 (2004), pp. 1794-1806.

[33] M.R. Amieva and H. Furthmayr, Subcellular localization of moesin in dynamic filopodia, retraction fibers, and other structures involved in substrate exploration, attachment, and cellcell contacts, Exp. Cell Res. 219 (1995), pp. 180-196.

[34] L.S. Price, J. Leng, M.A. Schwartz and G.M. Bokoch, Activation of Rac and Cdc42 by integrins mediates cell spreading, Mol. Biol. Cell 9 (1998), pp. 1863-1871.

[35] L. Haviv, Y. Brill-Karniely, R. Mahaffy, F. Backouche, A. Ben-Shaul, T.D. Pollard and A. Bernheim-Groswasser, Reconstitution of the transition from lamellipodium to filopodium in a membrane-free system, Proc. Natl. Acad. Sci. U. S. A. 103 (2006), pp. 4906-4911.

[36] A. Steffen, J. Faix, G.P. Resch, J. Linkner, J. Wehland, J.V. Small, K. Rottner and T.E. Stradal, Filopodia formation in the absence of functional WAVE- and Arp2/3-complexes, Mol. Biol. Cell 17 (2006), pp. 2581-2591.

[37] H. Tokuo, K. Mabuchi and M. Ikebe, The motor activity of myosin-X promotes actin fiber convergence at the cell periphery to initiate filopodia formation, J. Cell Biol. 179 (2007), pp. 229-238.

[38] P. Hotulainen and P. Lappalainen, Stress fibers are generated by two distinct actin assembly mechanisms in motile cells, J. Cell Biol. 173 (2006), pp. 383-394.

[39] P.A. Marignani and C.L. Carpenter, Vav2 is required for cell spreading, J. Cell Biol. 154 (2001), pp. 177-186.

[40] N.R. Filipenko, S. Attwell, C. Roskelley and S. Dedhar, Integrin-linked kinase activity regulates Rac- and Cdc42-mediated actin cytoskeleton reorganization via alpha-PIX, Oncogene 24 (2005), pp. 5837-5849.

[41] J.P. ten Klooster, Z.M. Jaffer, J. Chernoff and P.L. Hordijk, Targeting and activation of Rac1 are mediated by the exchange factor beta-Pix, J. Cell Biol. 172 (2006), pp. 759-769.

[42] M.A. del Pozo, N.B. Alderson, W.B. Kiosses, H.H. Chiang, R.G. Anderson and M.A. Schwartz, Integrins regulate Rac targeting by internalization of membrane domains, Science 303 (2004), pp. 839-842.

[43] M.A. del Pozo, N. Balasubramanian, N.B. Alderson, W.B. Kiosses, A. Grande-Garcia, R.G. Anderson and M.A. Schwartz, Phospho-caveolin-1 mediates integrin-regulated membrane domain internalization, Nat. Cell Biol. 7 (2005), pp. 901-908. 
[44] H. Tokuo and M. Ikebe, Myosin X transports Mena/VASP to the tip of filopodia, Biochem. Biophys. Res. Commun. 319 (2004), pp. 214-220.

[45] H. Zhang, J.S. Berg, Z. Li, Y. Wang, P. Lang, A.D. Sousa, A. Bhaskar, R.E. Cheney and S. Stromblad, Myosin-X provides a motor-based link between integrins and the cytoskeleton, Nat. Cell Biol. 6 (2004), pp. 523-531.

[46] A.B. Bohil, B.W. Robertson and R.E. Cheney, Myosin-X is a molecular motor that functions in filopodia formation, Proc. Natl. Acad. Sci. U. S. A. 103 (2006), pp. 12411-12416.

\section{Figures Legends}

Fig. 1. Time course of cell spreading on homogenous fibronectin fragments 7-10 Coat. Glass cover slip was coated for $1 \mathrm{~h}$ at $37^{\circ} \mathrm{C}$ with $5 \mu \mathrm{g} / \mathrm{ml}$ of FN7-10 fragment. Video-microscopy was carried out at $25^{\circ} \mathrm{C}$ to slow down the adhesion process using a Zeiss Axiovert 200M with motorized stage and equipped with an incubation chamber (XL, PeCon), filter wheel CCD black and white camera (CoolSnap HQ2, Roper Scientific). 63× Plan Apochromat, oil immersion N.A. 1.4 objective. Scale bar is $5 \mu \mathrm{m}$.

Fig. 2. Cell organization and time course of cell spreading on patterned surface. (A) Matrix arrays were prepared as described under Materials and methods with FN7-10 labeled with Alexa 350. Triple fluorescence microscopy was carried out. Blue is FN7-10 fragment labeled with Alexa 350 (adhesive spots of $4 \times 4 \mu \mathrm{m}$ ); red is actin labeled with TRITC Phalloidin; and green is vinculin staining using Alexa $488 \mathrm{Fab}_{2}$ secondary antibody (Molecular Probes). The black and white panels are phase contrast images. Distances between pitches are 4 and $8 \mu \mathrm{m}$ for upper and lower panels, respectively. (B) Video-microscopy was carried out as described under Materials and methods using a $32 \times$ Achrostigmat PH1 N.A. 0.40 objective. The pitch between adhesive spots is $8 \mu \mathrm{m}$. Scale bar is $10 \mu \mathrm{m}$.

Fig. 3. Close views of a spreading cell on the structured matrix. A phase contrast image corresponding to epifluorescence microscopy is presented for each image. (A) Left panels show a filopodium that has reached an adjacent adhesive island and begins to flatten on this surface while vinculin staining reveals the assembly of focal complexes. Blue is the Alexa 350 fluorescence of the adhesive spots; red is actin labeled with TRITC Phalloidin; and green is vinculin staining using Alexa $488 \mathrm{Fab}_{2}$ secondary antibody (Molecular Probes). Right panels are double epifluorescence microscopy of Rac1 using TRITC Fab' 2 secondary antibody (red) and Alexa 488-labeled fibronectin fragment (green) of spread cells on structured matrix. Arrows represent the accumulation of vinculin and Racl at the tips of filopodia in upper and lower panels, respectively. The lateral distance between adhesive spots is $16 \mu \mathrm{m}$. (B) Double labeling epifluorescence microscopy and phase contrast images of a cell with membrane enlargement at the contact of an adhesive plot of FN7-10. Red is F-actin labeled with TRITC Phalloidin, green is vinculin staining using Alexa $488 \mathrm{Fab}_{2}$ secondary antibody (Molecular Probes). The close view of the area in contact with the adhesive islands shows the assembly of a number of focal complexes stained by vinculin antibodies. The lateral distance between adhesive spots is $12 \mu \mathrm{m}$. (For interpretation of the references to colour in this figure legend, the reader is referred to the web version of this article.) 
Fig. 4. Inhibitory effect of cdc42 expression on cell spreading of NIH3T3 cells. The cells were grown overnight without fetal calf serum and plated for $4 \mathrm{~h}$ at $37^{\circ} \mathrm{C}$ in DMEM supplemented with serum as described under Materials and methods. (A) Cell spreading after $4 \mathrm{~h}$ at $37^{\circ} \mathrm{C}$ on homogenous coating with $5 \mu \mathrm{g} / \mathrm{ml}$ of FN7-10, scale bar is $20 \mu \mathrm{m}$. (B) Quantification of cell attachment and spreading on patterned FN7-10 microarrays after $4 \mathrm{~h}$ at $37^{\circ} \mathrm{C}$ using GFP-Cdc42V12 and GFP-Cdc42N17 expressing NIH3T3 cells.

Fig. 5. Cell spreading on Fibronectin 7-10 fragment microarrays of NIH3T3 expressing dominant-negative and constitutively active Rac1. The cells were grown overnight without fetal calf serum and plated on the arrays for $4 \mathrm{~h}$ at $37^{\circ} \mathrm{C}$ in DMEM supplemented with serum as described under Materials and methods. (A-C) F-actin staining using TRITC-labeled phalloidin. Panel $\mathrm{C}$ shows large lamellipodia that are observed with at least $50 \%$ of the cells. FN7-10 fragment is labeled with Alexa 350. (D-F) DIC microscopy using Zeiss Axiovert M200 inverted microscope.

Fig. 6. Effect of Rac1 expression on cell spreading on monoclonal anti- $\beta 1$ antibodies microarrays. Protein microarrays were carried out as described under Materials and methods. Anti-integrin MA1.2 antibodies microarrays does not sustain spreading of wild-type NIH 3T3 cells (A squares, and B upper left panel); conversely, homogenous coating with the same antibody allows NIH 3T3 cell spreading (B lower left panel). After stable transfection with constitutively active Rac1 V12, both microarrays (A triangles and B upper right panel) or homogenous coating (B lower right panel) with the anti-integrin antibodies result in cell spreading on the solid support. Panel B shows phase contrast microscopy images. Scale bar is $15 \mu \mathrm{m}$. 


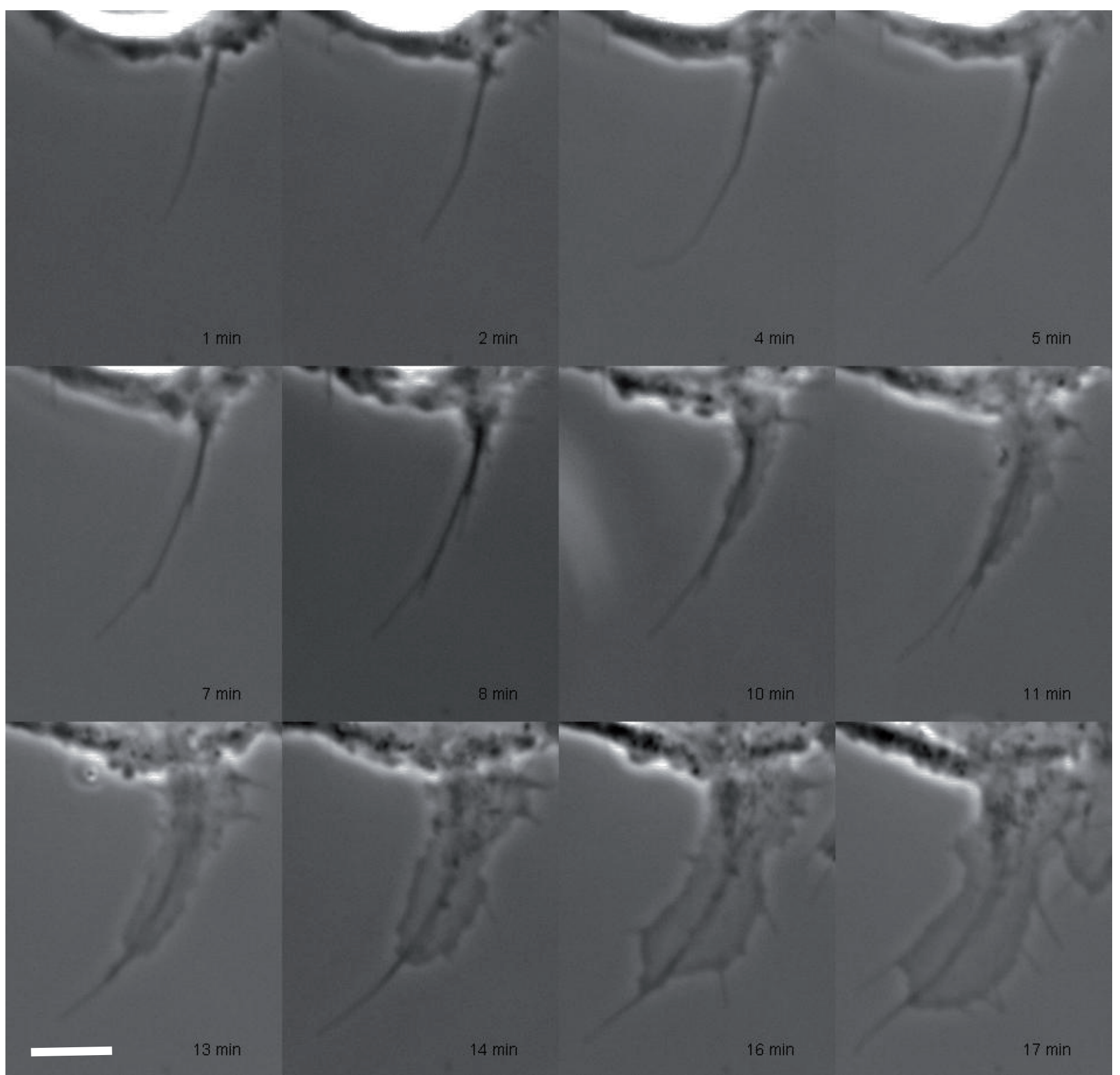

Guillou et al. Figure 1 

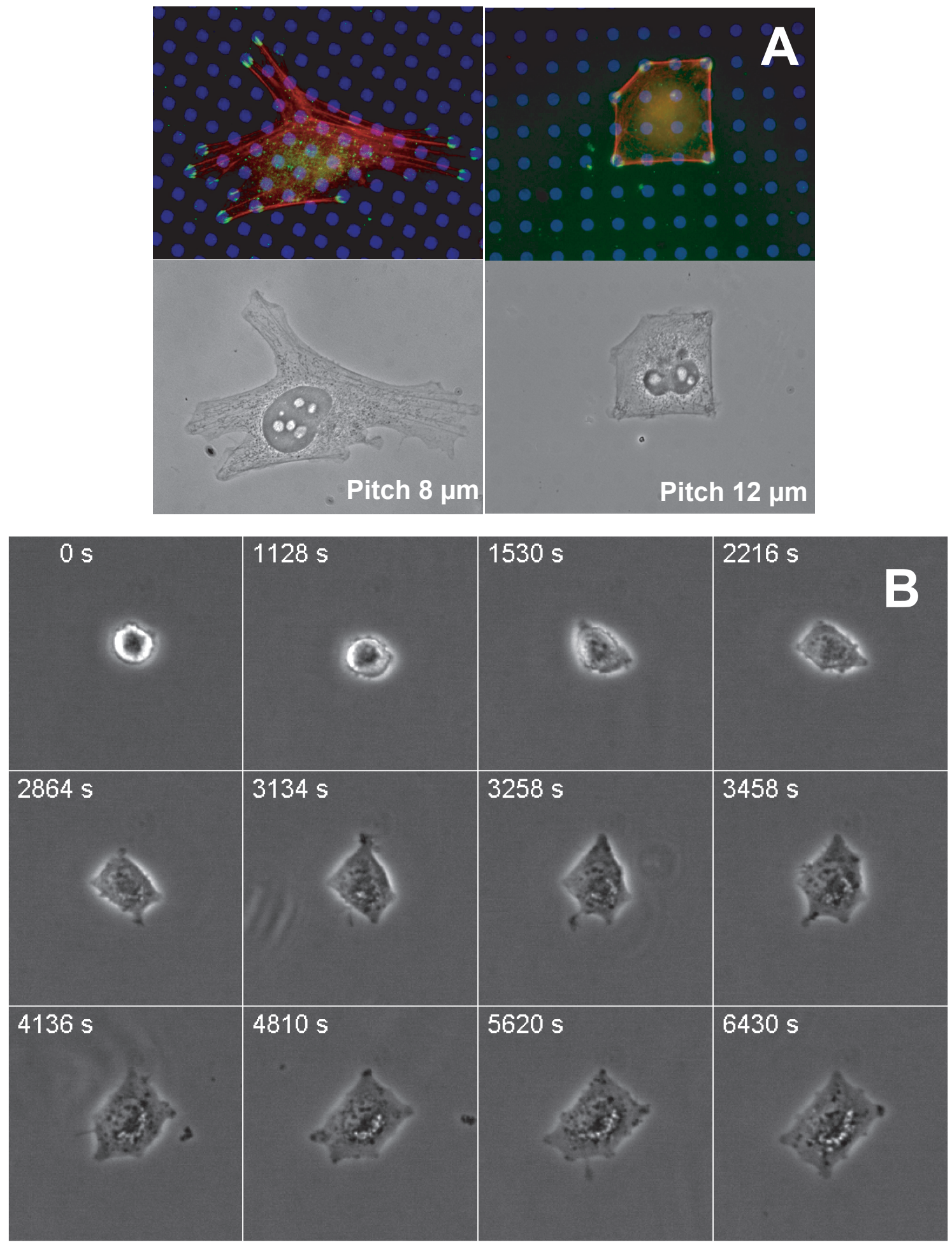

Figure 2 Guillou et al. 

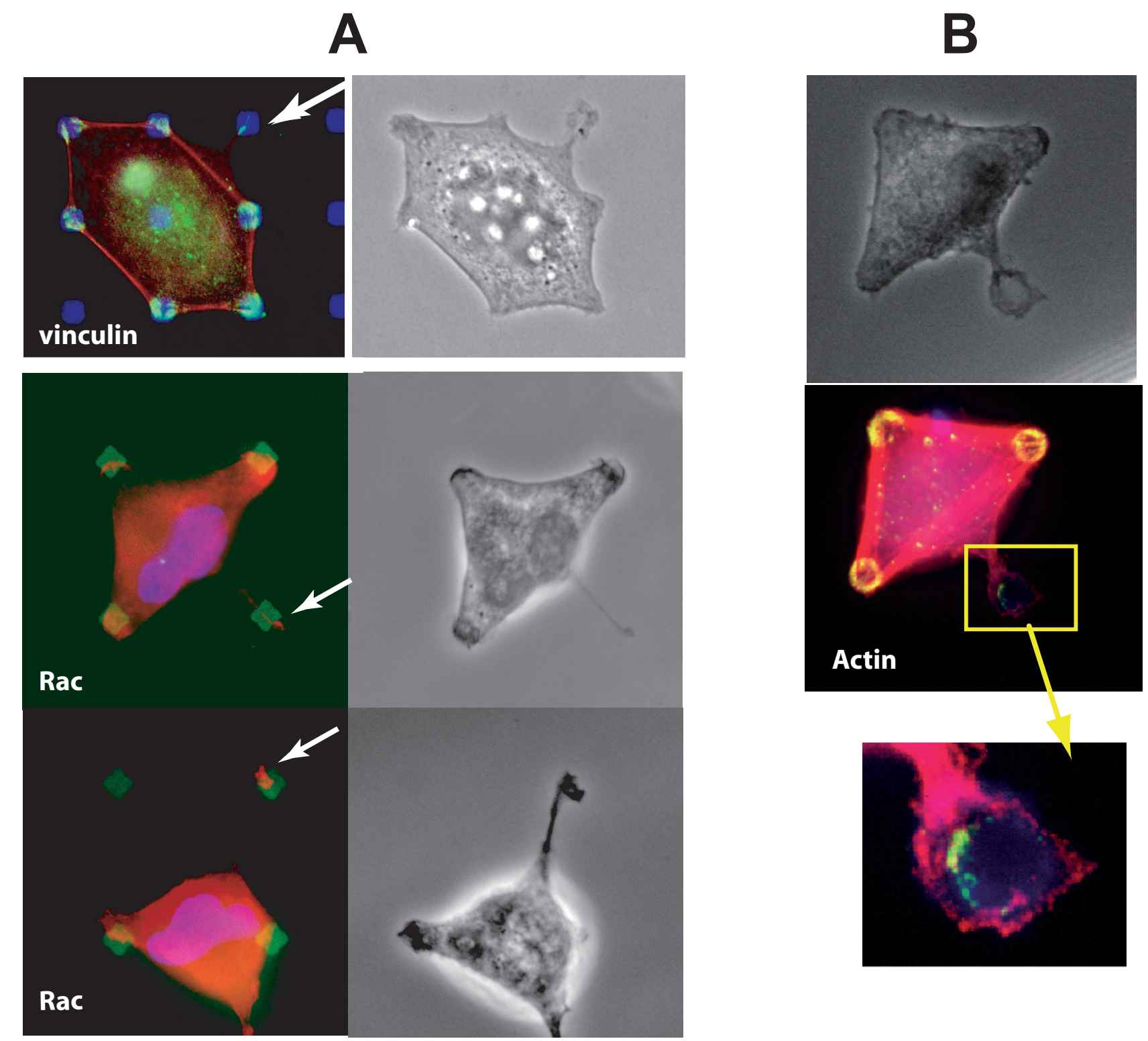

Figure 3 Guillou et al. 

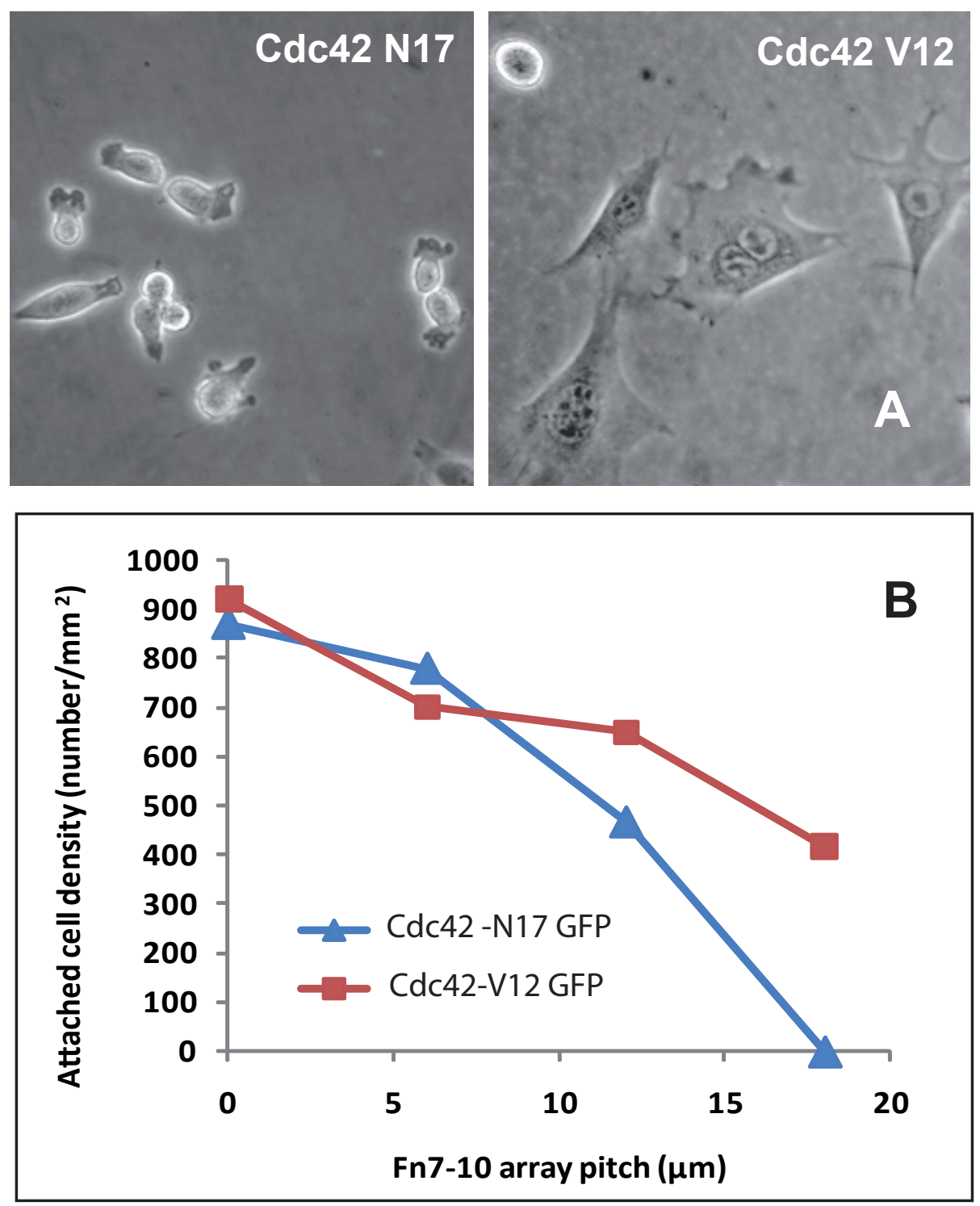

Figure 4, Guillou et al. 


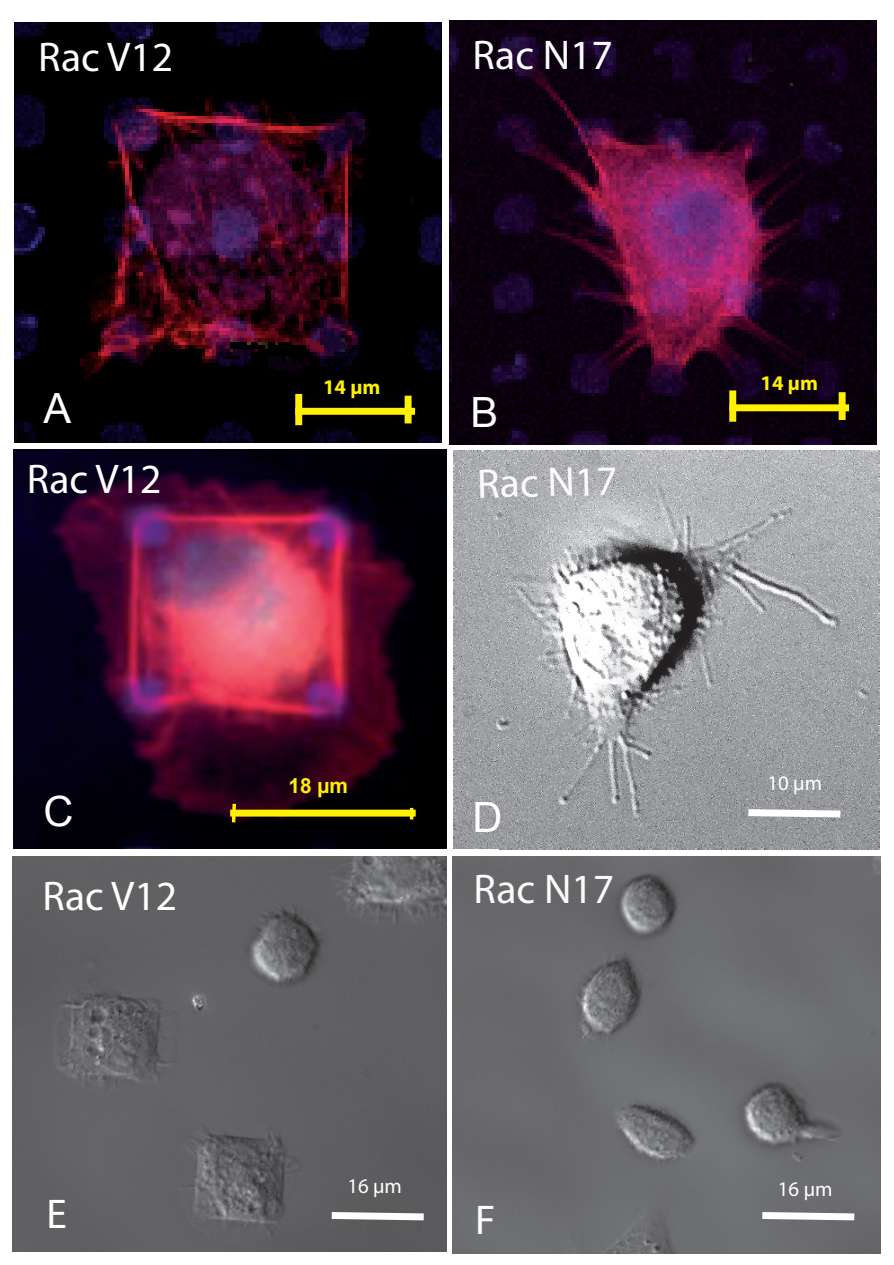

Figure 5. Guillou et al. 


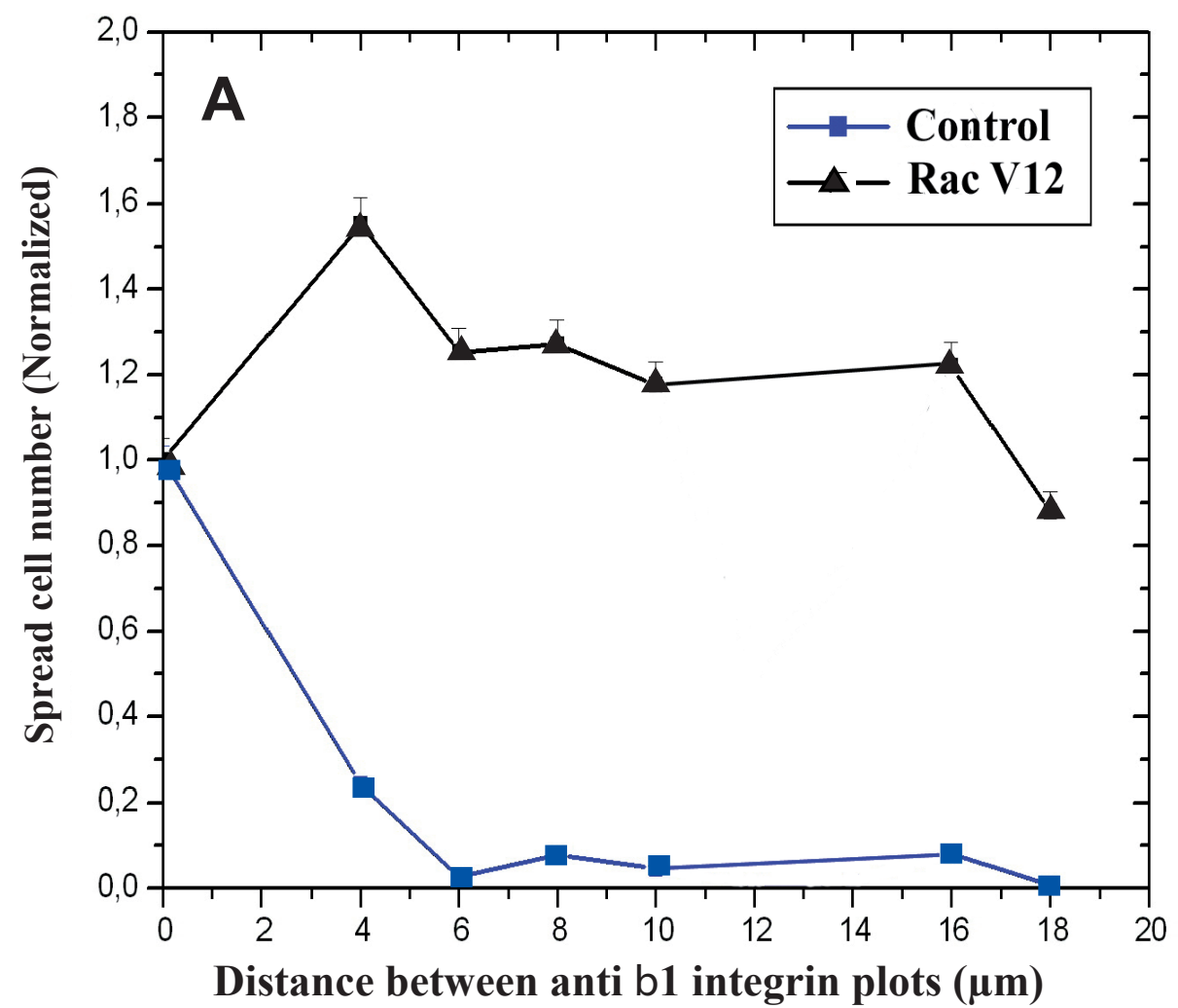

B

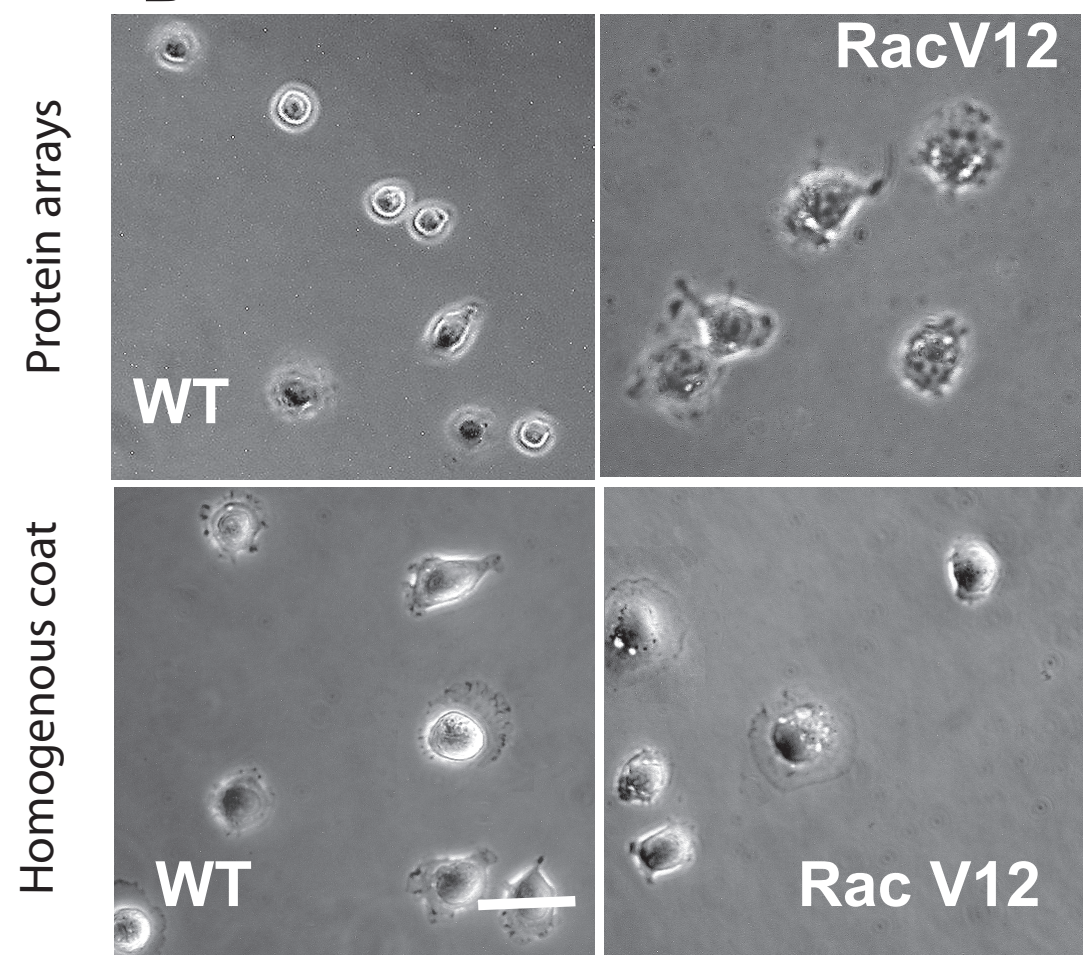

Figure 6. Guillou et al. 


\section{Appendix A. Supplementary data}

Movie 1. Time-lapse video-microscopy corresponding to the time frames shown in Fig. 7. Video-microscopy was carried out at $25^{\circ} \mathrm{C}$ on glass cover slip coated with $5 \mu \mathrm{g} / \mathrm{ml}$ of FN710. Transmission images were obtained using a $40 \times$ PlanApo N.A. 1.00 water immersion objective. Time lapse between frames is $2 \mathrm{~s}$.

Movie 2. Time-lapse video-microscopy of NIH3T3 cell spreading on FN7-10 arrays corresponding to the time frames shown in Fig. $2 \mathrm{~B}$ carried out at $37^{\circ} \mathrm{C}$. The space between adhesive spots is $8 \mu \mathrm{m}$. Phase contrast images were obtained with a Nikon CF M Planachro LWD $40 \times$, N.A. 0.55 objective. Time lapse between frames is $2 \mathrm{~s}$.

Movie 3. Time-lapse video-microscopy carried out at $37^{\circ} \mathrm{C}$ of NIH3T3 cell spreading on a large pitch FN7-10 array. The pitch of adhesive spots array is $16 \mu \mathrm{m}$. Phase contrast images were obtained with a $32 \times$ Achrostigmat PH1 N.A. 0.40 objective. Time lapse between frames is $1 \mathrm{~min}$.

Movie 4. (A) Time-lapse video-microscopy carried out at $37^{\circ} \mathrm{C}$ of NIH3T3 cell expressing Rac V12-GFP. The pitch of adhesive spots array is $12 \mu \mathrm{m}$. Transmission images were obtained using a 40× PlanApo N.A. 1.00 water immersion objective. Time lapse between frames is $2 \mathrm{~s}$.

Movie 5. Time-lapse video-microscopy carried out at $37^{\circ} \mathrm{C}$ of NIH3T3 cell expressing Rac V12-GFP. Fluorescent images were obtained using a 40× PlanApo N.A. 1.00 water immersion objective. Time lapse between frames is $2 \mathrm{~s}$. The movies correspond to S4A.

㬝Corresponding author. INSERM U823, Equipe DySAD, Institut Albert Bonniot, Site Santé, BP170, 38042 Grenoble cedex 09, France. 